\title{
Antarctic temperature changes during the last millennium: evaluation of simulations and reconstructions
}

Hugues Goosse (1), Martina Braida (2), Xavier Crosta (3), Aurélien Mairesse (1), Valérie Masson-Delmotte (4), Pierre Mathiot (1), Raphael Neukom (5), Hans Oerter (6), Gwenaelle Philippon (1), Hans Renssen (7), Barbara Stenni (2), Tas van Ommen (8), and Elie Verleyen (9)

(1) Université Catholique de Louvain, Earth and Life Institute, Centre de recherches sur la terre et le climat G. lemaître, Louvain-la-Neuve, Belgium (hugues.goosse@uclouvain.be, +32-(0)10-474722), (2) University of Trieste, Dipartimento di Matematica e Geoscienze, Trieste, Italy, (3) UMR-CNRS EPOC, Université Bordeaux I, Talence, France, (4) Laboratoire des Sciences du Climat et de l'Environnement (CEA-CNRS-UVSQ/IPSL), Gif-sur-Yvette, France, (5) Oeschger Centre for Climate Change Research, University of Bern, Switzerland, (6) Alfred-Wegener-Institut für Polar- und Meeresforschung in der Helmholtz-Gemeinschaft, Bremerhaven, Germany, (7) Cluster Earth \& Climate, Department of Earth Sciences, Vrije Universiteit Amsterdam, The Netherlands, (8) Australian Antarctic Division, Hobart, Tasmania, Australia, (9) Protistology and Aquatic Ecology, Ghent University, Ghent, Belgium

Temperature changes in Antarctica over the last millennium are investigated using proxy records, a set of simulations driven by natural and anthropogenic forcings and one simulation with data assimilation. Over Antarctica, a long term cooling trend in annual mean is simulated during the period 1000-1850. The main contributor to this cooling trend is the volcanic forcing, astronomical forcing playing a dominant role at seasonal timescale. Since 1850, all the models produce an Antarctic warming in response to the increase in greenhouse gas concentrations. We present a composite of Antarctic temperature, calculated by averaging seven temperature records derived from isotope measurements in ice cores. This simple approach is supported by the coherency displayed between model results at these data grid points and Antarctic mean temperature. The composite shows a weak multi-centennial cooling trend during the pre-industrial period and a warming after 1850 that is broadly consistent with model results. In both data and simulations, large regional variations are superimposed on this common signal, at decadal to centennial time scales. The model results appear spatially more consistent than ice core records. We conclude that more records are needed to resolve the complex spatial distribution of Antarctic temperature variations during the last millennium. 